Check for updates

Cite this: RSC Adv., 2019, 9, 30182

\section{Hybrid nickel-free graphene/porphyrin rings for photodegradation of emerging pollutants in water}

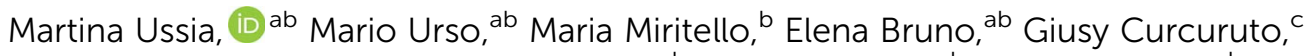 \\ Daniele Vitalini, ${ }^{c}$ Guglielmo G. Condorelli, ${ }^{d}$ Maria Cantarella, ${ }^{b}$ Vittorio Privitera ${ }^{b}$ \\ and Sabrina C. Carroccio (iD *bc
}

\begin{abstract}
A novel hybrid photoactive material based on graphene foam (G) coupled with porphyrin-based polymers (Porph rings) was formulated by using a time-saving procedure to remove nickel from the final device. Specifically, Porph rings were spin coated onto the G platform with the double function of a visible-light photocatalyst and protective agent during nickel etching. The characterization of G-Porph rings was assessed by Scanning Electron microscopy (SEM), X-ray photoelectron spectroscopy (XPS) and photoluminescence (PL). The novel material showed photocatalytic ability in degrading different classes of pollutants such as the herbicide 2,4 dichlorophenoxyacetic acid (2,4-D), polyethylene glycol (PEG) as an ingredient of care and health products, and also the methylene blue (MB) dye. UV-Vis spectroscopy, total organic carbon (TOC) and soft mass spectrometry techniques were used to monitor the photocatalytic process. The best performance in terms of photocatalytic efficiency was exhibited versus PEG and MB degradation. Furthermore, to determine the individual contribution of Reactive Oxygen Species (ROS) produced, free radical and hole scavenging tests were also carried out. Finally, a detailed map of the photocatalytic degradation mechanisms was proposed, reporting also the calculation of Porph rings' Highest Occupied Molecular Orbital (HOMO) and Lowest Occupied Molecular Orbital (LUMO) energy level values.
\end{abstract}

Received 14th August 2019 Accepted 18th September 2019

DOI: $10.1039 /$ c9ra06328e

rsc.li/rsc-advances

\section{Introduction}

The light induced processes enacted by organic semiconductors represent a promising environmentally friendly solution in several fields such as medicine, energy and water treatment

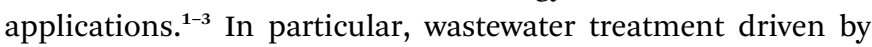
photocatalysis takes advantage of the use of light as a renewable energy source, allowing purification without adding further chemicals to the aqueous media. ${ }^{4}$ Importantly, photocatalytic based technologies can lead to the removal of emerging contaminants such as drugs, pesticides and chemicals deriving from personal care products (PCPs), becoming a more and more appealing approach to improving the traditional purification systems. ${ }^{4-8}$ The efficiency of this technology is based on the production of reactive oxygen species (ROS) in water, which are able to mineralize almost all organic pollutants. As well stated

${ }^{a}$ University of Catania, Department of Physics and Astronomy "Ettore Majorana", Via Santa Sofia 64, 95123, Catania, Italy

${ }^{b}$ CNR-IMM Catania, Via Santa Sofia 64, 95123, Catania, Italy. E-mail: sabrinacarola. carroccio@cnr.it

${ }^{c}$ CNR-IPCB, Via Paolo Gaifami 18, 95126, Catania, Italy

${ }^{d}$ University of Catania, Department of Chemistry and INSTM UdR Catania, Viale Andrea Doria 6, 95125 Catania, Italy

$\dagger$ Electronic supplementary information (ESI) available. See DOI: 10.1039/c9ra06328e in the literature, ${ }^{9}$ visible-light photocatalysis is mainly triggered by photosensitizers (i.e. porphyrin, phtalocianine...) through a spin forbidden intersystem crossing (ISC) process, leading to the production of singlet oxygen $\left({ }^{1} \mathrm{O}_{2}\right)$, which is the most reactive ROS specie..$^{\mathbf{1 0 , 1 1}}$ In this context, porphyrins represent one of the most used class of light-induced catalysts, finding applications in many fields including water remediation. ${ }^{9-16}$ Nevertheless, the ISC for such kind of materials is strongly limited by rapid electron-hole recombination between the singlet excited state and the ground state, mainly due to aggregation phenomena. ${ }^{\mathbf{1 3 , 1 6}}$ To turn this limitation, the combination of porphyrins with carbon-based nanostructures, such as carbon nanotubes and graphene $\mathrm{e}^{17-23}$ was exploited. Indeed, these materials are considered ideal candidates as co-catalyst carriers, having specific features such as high-surface area and conjugated networks. ${ }^{20,21}$

It was demonstrated as the non-covalent assembly of porphyrin based polymers (Porph rings) with a graphene platform supported by nickel, represents an efficient method to avoid the electron-hole recombination mechanism as well as other critical issues deriving from the use of $G$ derivatives. ${ }^{19,24-26}$ The present paper describes the formulation of a novel nickel free photoactive material, its characterization as well as the related photocatalytic attitudes on different classes of contaminants. Undeniably, Ni removal is strictly required for applications in 
water and medical fields, being an allergen and a water contaminant $(\geq 0.010 \mathrm{ppm}$ ) harmful for aquatic and human life.

In light of this, a time-saving method to remove $\mathrm{Ni}$ from $\mathrm{G}$ avoiding the collapse of the $3 \mathrm{D}$ structure during the nickeletching was developed. ${ }^{27}$

3D collapse constitutes critical issue for the production of $\mathrm{G}$ foam from a Ni template by chemical vapor deposition (CVD) ${ }^{28}$ After growing onto the Ni substrate, the production of $\mathrm{G}$ foam required a multi-step process which includes polymer infiltration, etching by acidic solution, solvent washing to dissolve the polymer coating and finally, drying or lyophilization. These latter two steps are crucial to obtain a foam-like network graphene, avoiding its structural collapse.

The photocatalytic activity of as prepared hybrid material was monitored by UV-Vis, TOC and MS techniques selecting as target pollutants the pesticide 2,4-dichlorophenoxyacetic acid (2,4-D), MB dye, and the water soluble polyethylene-glycol (PEG). The 2,4$\mathrm{D}$ herbicide is widely used in agriculture, although its toxicity is well known along with a poorly water biodegradability. ${ }^{\mathbf{2 9}, 30}$ Concerning the PEGs, controversial opinions were reported on its safe environmental use. This hydrophilic polymer, which is often included in several copolymeric formulations for a wide range of applications, is considered biodegradable up to 10 monomeric units. However higher molar masses of PEG are commonly used for cosmetics, detergents and biomedical purposes, becoming an insidious threat for the environment. ${ }^{31-34}$ Finally, MB being one of the most used simulant dye, was selected as a reference to compare our results with data reported in the literature, ${ }^{22,35-37}$ as well as to determine and discriminate among the ROS production during photo-process.

\section{Results and discussion}

The graphene platform used to prepare the device was obtained by CVD deposition on a Nickel foam template (see experimental section). To cover the nickel-graphene foam (Ni-G), a water insoluble polymeric materials based on porphyrin rings having a $M_{\mathrm{w}}$ of 10600 Da were properly selected ${ }^{19,38}$ as photoactive coating film. The hybrid material preparation is reported and discussed in the following sections.

\subsection{Nickel free-graphene foam/Porph rings (Ni free-G/Porph rings) composite preparation}

As well stated, the etching procedure to eliminate the nickel catalyst substrate requires the graphene protection by spincoating polymers such as commercial polymethylmethacrylate (PMMA) or polydimethyl siloxane (PDMS). ${ }^{39}$ Subsequently, the sample is etched using $\mathrm{HCl} 3 \mathrm{M}$, dried and immersed in hot-solvent to remove the polymer, obtaining the final product to employ. However, this step induces a 3D structure collapse caused by the liquid capillary force involved during solvent evaporation, that provides a thinner $\mathrm{G}$ than the pristine Ni-Foam..$^{40}$ Thus, polymer removal drastically limits the use of $\mathrm{Ni}$ free- $\mathrm{G}$ as freestanding materials. In recent papers, concerning the formulation of conducting $\mathrm{G}$ foam devices, the collapse of the 3D structure was avoided by non-removing the protective polymer coating that remains as a part of the final material. ${ }^{39,41}$ Taking into account this strategy, the novelty here reported consists in preparing the Ni free sample in a one-step process preserving via photocatalyst coating, the G support [see Fig. 1a-d]. In particular, Porph rings were used with the double function of the photoactive part of the device and protective coverage, as well. To successfully deposit the polymer by spin-coating, Porph rings were synthesized with an appropriate $M_{\mathrm{w}}$ and characterized by using gel permeation chromatography and mass spectrometry (Table S1 $\uparrow$ and Fig. S1a and $\mathrm{b} \dagger)$. Thus, the hybrid system was etched. This treatment avoided the collapse of the network obtaining the final photoactive material without any additional step. The asprepared nickel free sample was subjected to morphological and physico-chemical characterizations reported as follows.

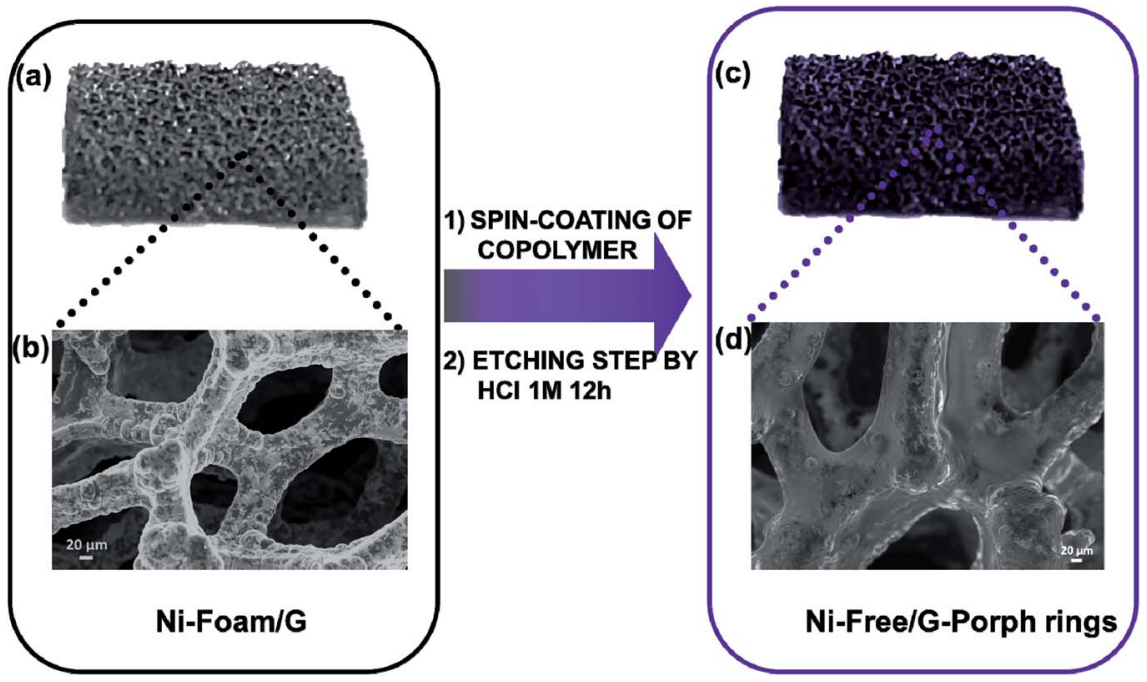

Fig. 1 (a) and (b) As-grown 3DG coated with a thin layer of Porph rings by a spin-coating deposition method and (c) and (d) Ni free-G/Porph rings sample after etching by hot $\mathrm{HCl} 1 \mathrm{M}$ solution maintaining the typical 3D graphene structure. 


\subsection{Graphene 3D characterization}

2.2.1 SEM analysis. The pristine Ni-foam possesses a 3D porous structure and a tortoiseshell-like morphology [see Fig. 2a] with pores sizes ranging from 60 to $130 \mu \mathrm{m}$. The SEM images of the as-deposited graphene are reported in Fig. $2 b$ revealing that the graphene adheres to the surface of the nickel foam, reproducing its morphology. ${ }^{19,38}$ As described in the experimental part, the $\mathrm{G}$ was drop-coated with the cyclic polymer obtaining a homogeneous coverage, as shown in Fig. 2c. Fig. 2d shows that the morphology of the Ni-free/G-Porph rings sample appears unchanged after the etching procedure, demonstrating the efficacy of the polymer-layer onto the graphene surface to protect the G network from the collapse of the structure.

2.2.2 XPS analysis. To ascertain that the etching procedure does not affect the nature of the polymer coating and its related interactions with the G substrate, we performed XPS analysis. Furthermore, XPS provides also information about the effective removal of Nickel. Fig. 3a reports the XPS $\mathrm{N}$ 1s region of the Nifree/G-Porph rings sample. The signal consists of two components centered at $400.2 \mathrm{eV}$ and at $398.2 \mathrm{eV}$, indicating the presence of the pyrrolic $\left(-\mathrm{NH}^{-}\right)$and to the iminic $(-\mathrm{N}=)$ species of the porphyrin rings respectively. ${ }^{19,41,42}$ Furthermore, the C 1s region [Fig. 3b] reveals two components positioned at $285.0 \mathrm{eV}$ (FWHM of $1.5 \mathrm{eV}$ ) and at $286.5 \mathrm{eV}$ (FWHM of $1.7 \mathrm{eV}$ ), due respectively to the $\mathrm{C}-\mathrm{C}, \mathrm{C}=\mathrm{C}, \mathrm{C}-\mathrm{H}$ of the graphene and to the $\mathrm{C}-\mathrm{O}, \mathrm{C}=\mathrm{N}, \mathrm{C}-\mathrm{N}$ species of the $3 \mathrm{DG}$ copolymer-porphyrin structure.

Fig. S2 (see ESI $\dagger$ ), reporting the Ni 2p region, does not show the typical signals of Ni suggesting that the metal was effectively removed. However, to confirm the nickel removal after etching, we also performed a quantitative analysis by using Inductively Coupled Plasma-Mass Spectrometry (ICP-MS). In Table 1 the nickel contents are reported before and after sample etching. As it is possible to observe, the residual $\mathrm{Ni}$ amount after the etching procedure, was lower than $100 \mu \mathrm{g} \mathrm{cm} \mathrm{cm}^{-2}$. Furthermore, during the photocatalytic treatment, after 6 hours of irradiation, the Ni content in water was measured, obtaining a value of $20 \mu \mathrm{g}$ $\mathrm{cm}^{-2}$.

2.2.3 Photoluminescence measurements. The charge electron-transfer processes in hybrid systems were evaluated by analyzing the influence of the $G$ presence on the optical emission of the polyporphyrins. ${ }^{\mathbf{4 3 , 4 4}}$ Since PL emission strongly depends on the radiative recombination rate of excited electron-hole pairs, additional electron pathways occurred. As reported in the literature, coupling of photoactive systems with graphene-based materials produces a quenching in the PL intensity induced by additional electron-transfer process due to the $\mathrm{G}$ interaction at material interfaces. ${ }^{22,23}$ Fig. 4 compares the $\mathrm{PL}$ emission collected under excitation at $325 \mathrm{~nm}$ on Ni-foam/ 3DG and on Ni-free/3DG with a reference Porph rings copolyformal on pristine Ni-foam (Ni-Foam/Porph rings). In all cases the PL emission exhibits a broad band composed by two peaks centered at 660 and $720 \mathrm{~nm}$, related to their $Q_{X}(0-0)$ and $Q_{X}(0-$ 1) transitions respectively.

However, an effective quenching in the case of Ni-foam/GPorph rings and a quasi-total disappearance of characteristic emission band for the Ni-Free/G-Porph rings, with a slightly blue-shift of the signals are evident. This key result validates that $\pi-\pi$ interactions between porphyrin aromatic moieties and graphene take place, allowing a remarkable electron transfer at the polymer interface. ${ }^{\mathbf{4 4}, 45}$ Different phenomena could justify the further PL quenching after nickel removal, such as the change in graphene electronic structure as well as an enhanced graphene $\pi$-delocalization after electron injection..$^{20,43,45,46}$

2.2.4 Cyclic voltammetry measurements. To gain a better insight into the photodegradation mechanisms, it is very

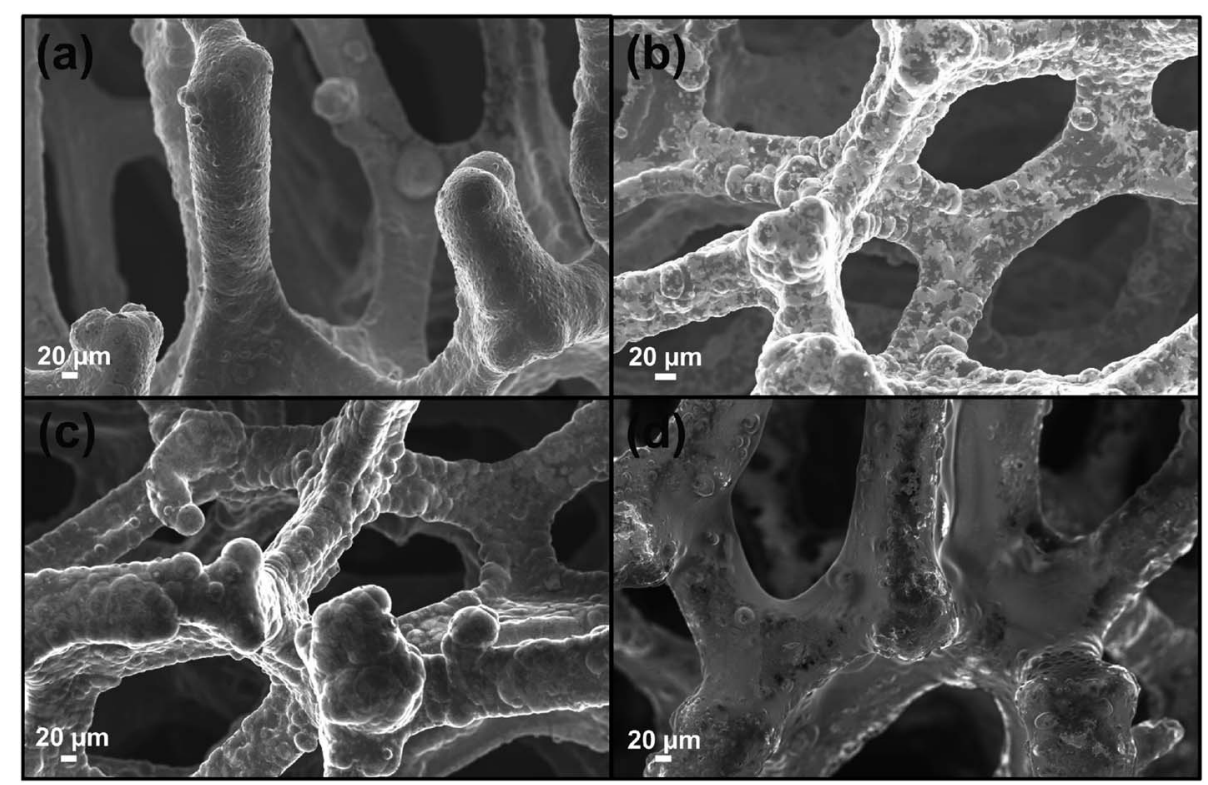

Fig. 2 SEM images obtained in the inlens mode of (a) Ni-foam (b) Ni-Foam/G (c) Ni-Foam/G-Porph rings (d) Ni-free/G-Porph rings. 
(a)

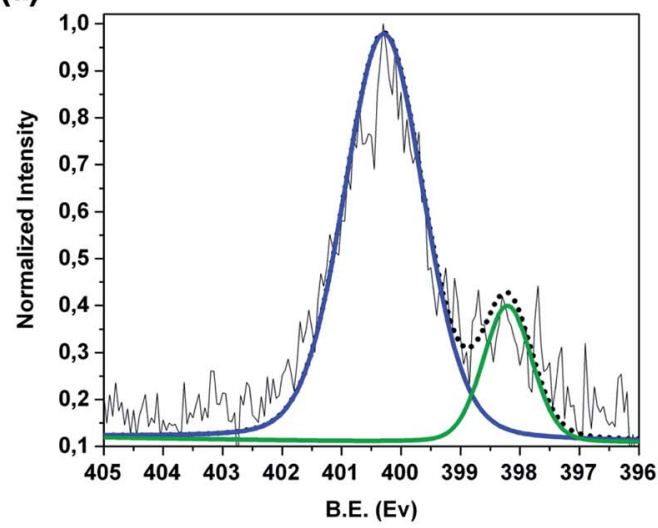

(b)

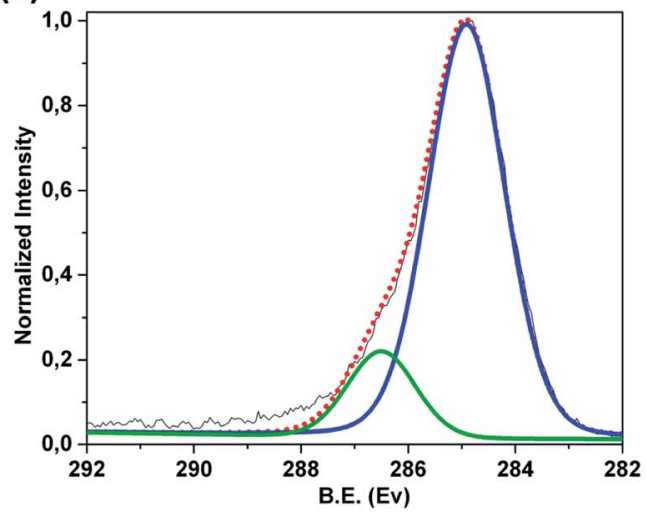

Fig. 3 XPS spectra of $\mathrm{Ni}$-free/G-Porph rings sample in the (a) high resolution $\mathrm{N}$ 1s region and (b) high resolution $\mathrm{C} 1 \mathrm{~s}$ region.

important to understand the electronic properties of the Porph rings (i.e. HOMO and LUMO levels). Although the cyclic voltammetry (CV) represents an appropriate tool to estimate the Frontier orbitals, it often requires the combination with other techniques, such as UV-Vis spectroscopy. ${ }^{47,48}$ In this work, CV curves were referenced to ferrocene by taking $E_{1 / 2}\left(\mathrm{Fc} / \mathrm{Fc}^{+}\right)=$ $0.429 \mathrm{~V}$ vs. SCE (Fig. S3†). From the inspection of the CV measurements on the Porph rings reported in Fig. 5, the small oxidation and reduction peaks at $\sim 1.6$ and $\sim 0.4 \mathrm{~V} v s$. $\mathrm{Fc} / \mathrm{Fc}^{+}$are attributed to traces of the residue monomer molecules, as demonstrated by the $\mathrm{CV}$ curve of the porphyrin monomer solution (Fig. S5 $\dagger$ ). The presence of residue porphyrin monomer was also confirmed by the MALDI spectra (Fig. S1†). Thus, the high and irreversible reduction peak at $-0.6 \pm 0.2 \mathrm{~V} v s . \mathrm{Fc} / \mathrm{Fc}^{+}$ was ascribed to the Porph rings (half of FWHM was used to evaluate the error). HOMO ( $\left.E_{\text {Hомо }}\right)$ and LUMO $\left(E_{\text {LUMO }}\right)$ energy levels can be estimated from oxidation $\left(E_{\mathrm{ox}}\right)$ and reduction $\left(E_{\mathrm{red}}\right)$ peaks potential as follows:

$$
\begin{aligned}
& E_{\mathrm{HOMO}}=-\left(E_{\mathrm{ox}} v s . \mathrm{Fc} / \mathrm{Fc}^{+}+4.8\right) \mathrm{eV} 1 \\
& E_{\mathrm{LUMO}}=-\left(\mathrm{E}_{\mathrm{red}} v s . \mathrm{Fc} / \mathrm{Fc}^{+}+4.8\right) \mathrm{eV} 2
\end{aligned}
$$

where $4.8 \mathrm{eV}$ is the formal potential of the $\mathrm{Fc} / \mathrm{Fc}^{+}$redox couple in the Fermi scale. ${ }^{48} \mathrm{CV}$ curves were referenced to ferrocene by taking $E_{1 / 2}\left(\mathrm{Fc} / \mathrm{Fc}^{+}\right)=0.429 \mathrm{~V} v$ s. SCE (Fig. S5 $\dagger$ ). According to eqn (2), the LUMO energy level of the Porph rings was estimated to $E_{\text {LUMO }}=-4.2 \pm 0.2 \mathrm{eV}$. On the other hand, by UV-Vis absorption measurement (Fig. S6 $\dagger$ ) we measured the optical bandgap $\left(E_{\mathrm{g}}\right)$ as $E_{\mathrm{g}}=2.2 \mathrm{eV}$ and thus we estimated the HOMO energy level as $E_{\text {Номо }}=E_{\mathrm{LUMO}}-E_{\mathrm{g}}$, finding the eqn (1) $E_{\mathrm{HOMO}}=-6.4 \pm$ $0.2 \mathrm{eV}^{49-51}$ To our knowledge, this is the first time that HOMO and LUMO energy levels of cyclic porphyrins-based copolyformal are measured by $\mathrm{CV}$.

\section{Photocatalytic degradation tests}

The photocatalytic activity of Ni-free/G-Porph rings under Visible-Light (VL) irradiation was tested by monitoring the degradation of MB, 2,4-D and PEG (see Fig. 6).

In Fig. 7a-b the ESI-MS spectra of (a) 2,4-D pristine solution and (b) after 6 hours of visible-light irradiation in the presence of the photocatalyst are reported. As shown from the spectra,

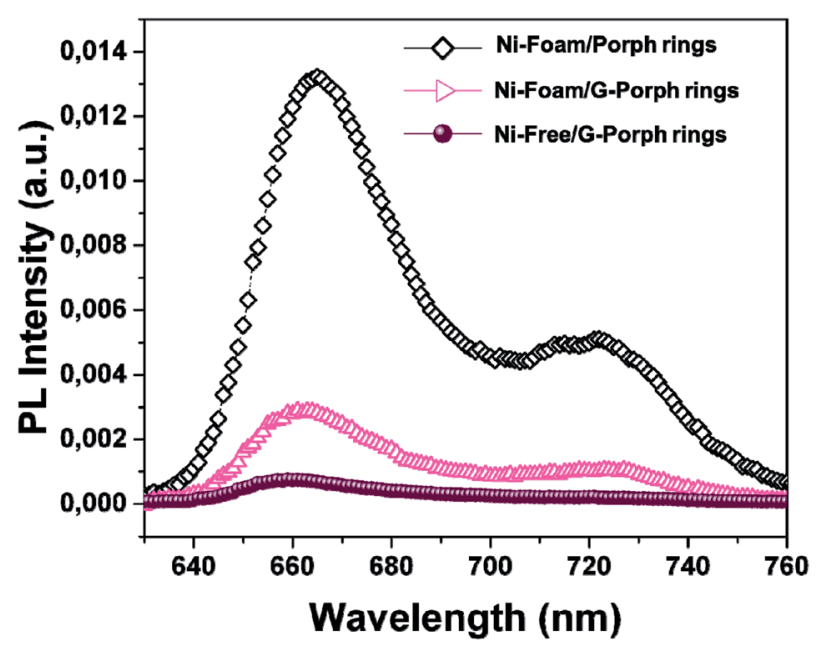

Fig. 4 PL spectra of Ni-Foam/Porph rings (black rumble), Ni-Foam/GPorph rings (fuchsia triangle), Ni-free/G-Porph rings (purple circle) collected upon excitation at $325 \mathrm{~nm}$.

Table 1 Nickel content in $G$ samples before and after etching

\begin{tabular}{llll}
\hline Ni-Foam/3DG & Ni-Foam/Porph rings & $\begin{array}{l}\text { Ni-Free/3DG } \\
\text { Porph rings }\end{array}$ & $\begin{array}{l}\text { Ni-Free/3DG Porph } \\
\text { rings (after 6 h irradiation) }\end{array}$ \\
\hline $165736 \mathrm{mg} \mathrm{cm}^{-2}$ & $166066 \mathrm{mg} \mathrm{cm}^{-2}$ & $94 \mu \mathrm{g} \mathrm{cm}^{-2}$ & $20 \mu \mathrm{g} \mathrm{cm} \mathrm{cm}^{-2}$
\end{tabular}




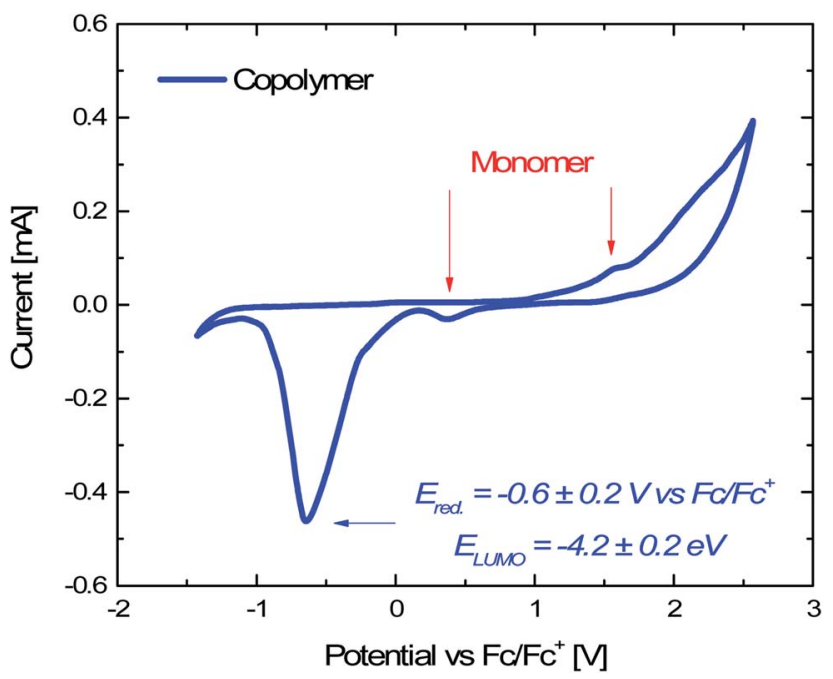

Fig. 5 Cyclic voltammetry of Porph rings recorded at $25 \mathrm{mV} \mathrm{s}^{-1}$ scan rate in $0.1 \mathrm{M}$ TBAPF6 in dichloromethane solution. Ferrocene was used as internal standard.

the ESI-MS peaks associated to the 2,4-D molecules $(\mathrm{m} / \mathrm{z}$ at $218.95 / 220.95)$, disappeared after the photocatalytic procedure. Conversely, the lesser abundant signals at $\mathrm{m} / \mathrm{z} 160.95 / 162.94$ assigned to the main degradation product 2,4-dichlorophenol, ${ }^{30}$ significantly increased after the photocatalyst addition. The initial presence of 2,4-dichlorophenol molecules in the pristine sample derived from synthesis impurity. Although the formation of by-products indicated the occurrence of herbicide degradation, 2,4-D mineralization was not successfully achieved under these experimental conditions. Indeed, as revealed from UV-Vis and TOC analyses (see Fig. S7†), absorbance profiles as well as TOC values remained unchanged during the photo-exposure, most likely due to the formation of recalcitrant 2,4-dichlorophenol and other chlorinated species in solution. As expected, these intermediates are very difficult to mineralize by vis-light photocatalytic process ${ }^{52,53}$ requiring more severe experimental conditions.
Photodegradation ability of hybrid material was tested also on PEG solution. Among water soluble polymers, PEG is constituted by a simple molecular structure representing an adequate compound for studying photocatalytic degradation features. To this purpose, a sample having a narrow polydispersity $(D=109)$ with an $M_{\mathrm{w}}$ of 1900 Da was selected to allow the simultaneously determination of molar masses and degradation products as well, by MALDI methods during photoexposure. Fig. $8 \mathrm{a}-\mathrm{c}$ reported MALDI TOF spectra collected in reflectron mode of (a) pristine PEG sample; after (b) 3 hours and, (c) 6 hours of photo-exposure in the presence of the photocatalyst. As it is possible to notice from the figure, relative abundance of signals corresponding to PEG macromolecular chains, significantly decreased (see also Fig. S8†) as the exposure time proceeded, producing oxidized polymer chains at lower mass range. Degradation products deriving from the photocatalytic process are assigned to PEG oligomers having formic acid, aldehydic and alcoholic end groups (see Fig. S9†). After 6 hours, progressively degradation took place, leading to the disappearing of initial PEO distribution with the formation of much lower macromolecular oxidized chains, that cannot be detected being lower than the mass range inferior limit. Photochemical oxidation mechanism proposed in the literature for $\mathrm{PEG}^{32-34,51}$ well fitted with the products revealed by MALDI, involving mainly the ROS attack on $\mathrm{CH}_{2}$ groups with a random chain scission pathway. At this stage mineralization measured by TOC revealed $85 \%$ of PEG removal (Fig. 9).

The photocatalytic activity versus MB (Fig. 10) was also tested, by comparing the results with those reported in the literature for similar devices where dyes were used as reference pollutants. ${ }^{\mathbf{5 4 5 5}}$ The dark adsorption data of all the samples are reported in Fig. 10a evidencing a major adsorption in the case of the Ni-free material. This value was most likely due to hollow channels of $\mathrm{G}$, formed after Ni removal and exposed to the MB solution. When the adsorption/ desorption equilibrium was reached, samples were exposed to the visible light.

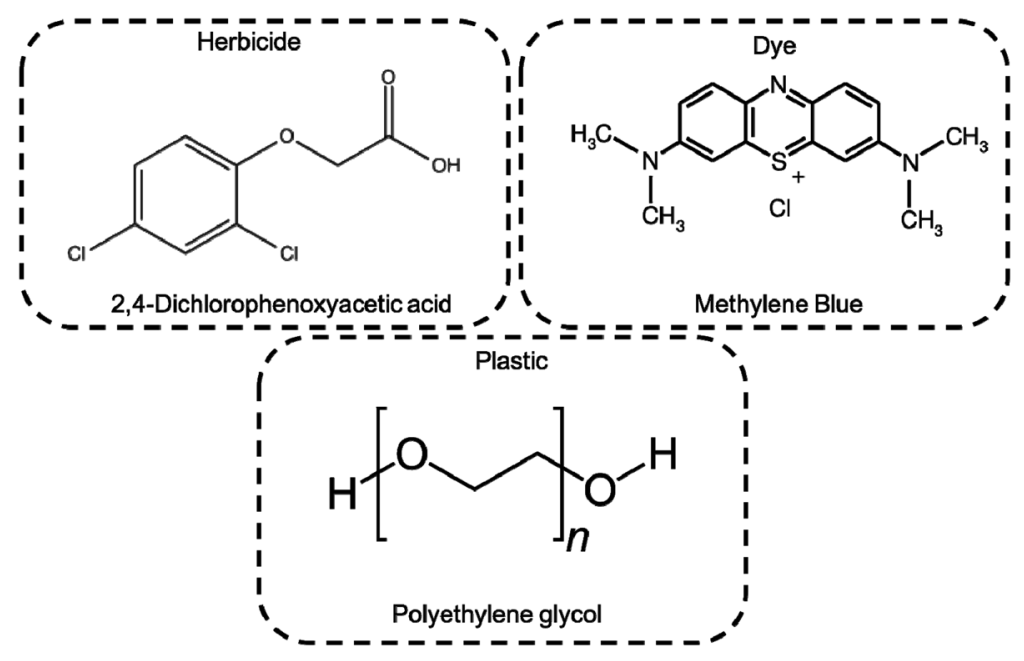

Fig. 6 Structures of tested pollutants. 

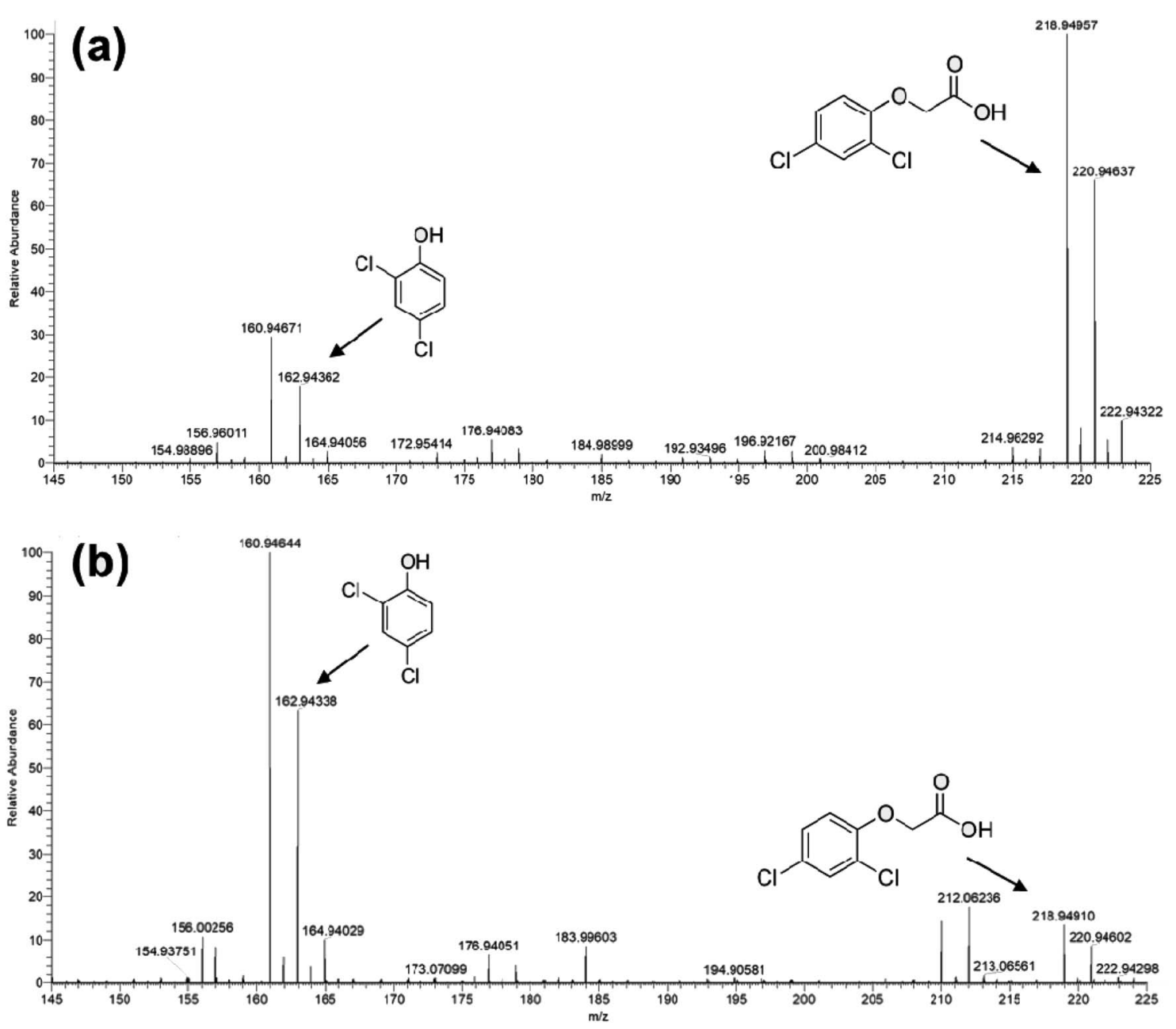

Fig. 7 ESI-MS spectra collected in negative ion mode for: (a) untreated 2,4 D solution and (b) Visible-light photo-exposed 2,4-D solution after 6 hours of irradiation time.

Data collected after 120 minutes of light irradiation revealed that $\mathrm{Ni}$-free/G-Porph rings degraded $93.4 \%$ of $\mathrm{MB}$ [see also Fig. 10b], whereas the Ni-foam/G-Porph rings showed $60 \%$ of photo-degradative capacity. As expected, the Ni Foam/G, used as external reference did not exhibit any MB degradation. These results indicate that the Ni-removal plays a key-role in the photodegradation, eliminating almost all the MB after only 120 minutes of VL irradiation. According with PL measurements, the boost of the photocatalytic efficiency was reasonable due to a more effective electron-transfer process at the graphene interface. Compared with the performance of similar devices ${ }^{54,55}$ monitored by using dyes degradation tests, this hybrid sample offered the great advantage to use a standalone system, ${ }^{19,54}$ containing lower amount of photocatalysts $\left(0.4 \mathrm{mg} \mathrm{cm}^{-2}\right),,^{55,56}$ to obtain valuable photocatalytic properties under visible light irradiation.

\subsection{ROS determination}

The photochemistry of the material was investigated by the qualitative evaluation of the ROS produced, by following methods described in ref. 21, 32 and 33. Generally, when a photocatalyst is irradiated by light, ROS such as hydroxyl radical $\left(\mathrm{OH}^{\circ}\right)$, superoxide radicals $\left(\mathrm{O}_{2}{ }^{-{ }^{-}}\right)$and the singlet oxygen $\left({ }^{1} \mathrm{O}_{2}\right)$ are generated.$^{54}$ These reactive species are able to degrade the pollutants by redox reactions. ${ }^{9}$ If compared with inorganic photo-catalysts, the formation of ${ }^{1} \mathrm{O}_{2}$ is a distinctive feature of photosensitizers. The singlet oxygen is a selective oxidant specie able to promptly react with unsaturated double bonds, phenols, sulfides, amines and other electron-donor compounds. ${ }^{57}$ In addition, it explicates a highly cytotoxic action versus cells and microorganisms becoming particularly attractive in wastewater treatment for its dual function of decontamination and disinfection. ${ }^{58}$

The discrimination among the produced ROS can be obtained by introducing specific radical-trapping agents (Fig. 11) during the light exposure. These scavenger molecules interacting with the related photo-generated radicals, inhibit their reaction with the organic pollutant. In particular, ethylene diamine tetraacetic acid (EDTA), $t$-BuOH, nitro-blue tetrazolium (NBT) and 9,10-anthracene-diyl-bis(methylene)dimalonic acid (ABDA), can be efficiently used to scavenge photogenerated holes, hydroxyl radical, superoxide radical and singlet oxygen respectively. ${ }^{35,36,57}$ Consequently, the photochemistry mechanisms involved during photoexcitation can 


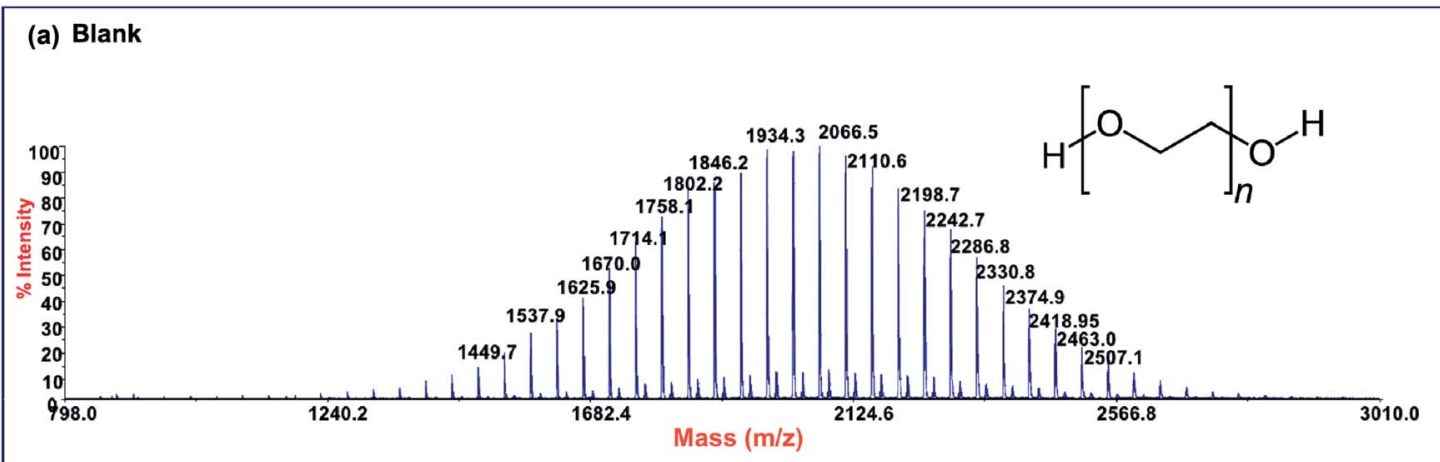

(b) PEG 3 Hours

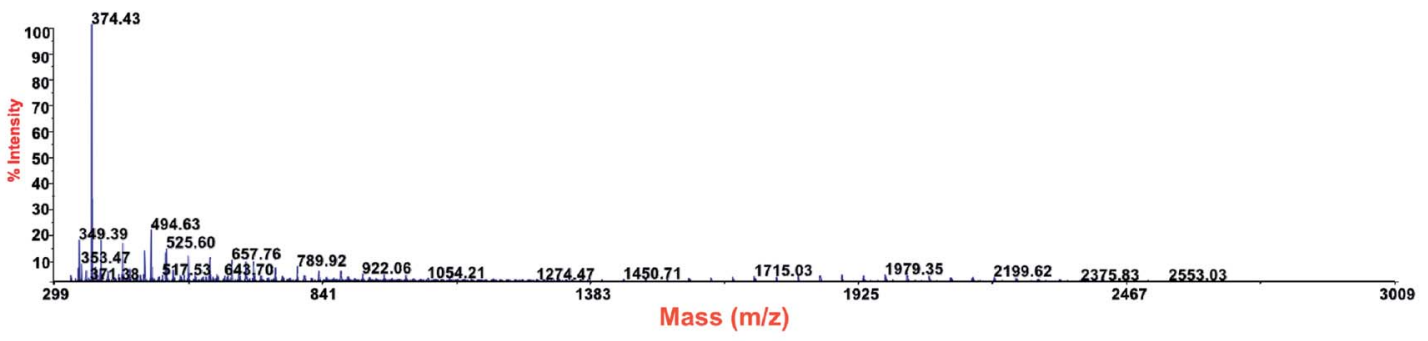

(c) PEG 6 Hours

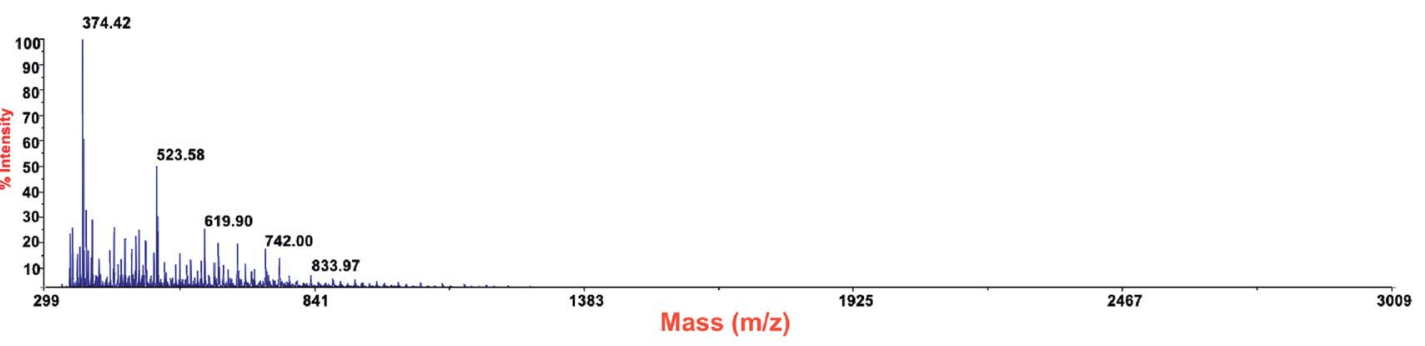

Fig. 8 MALDI-TOF spectra of (a) pristine PEG sample and after (b) 3 hours and (c) 6 hours of photo-exposure.

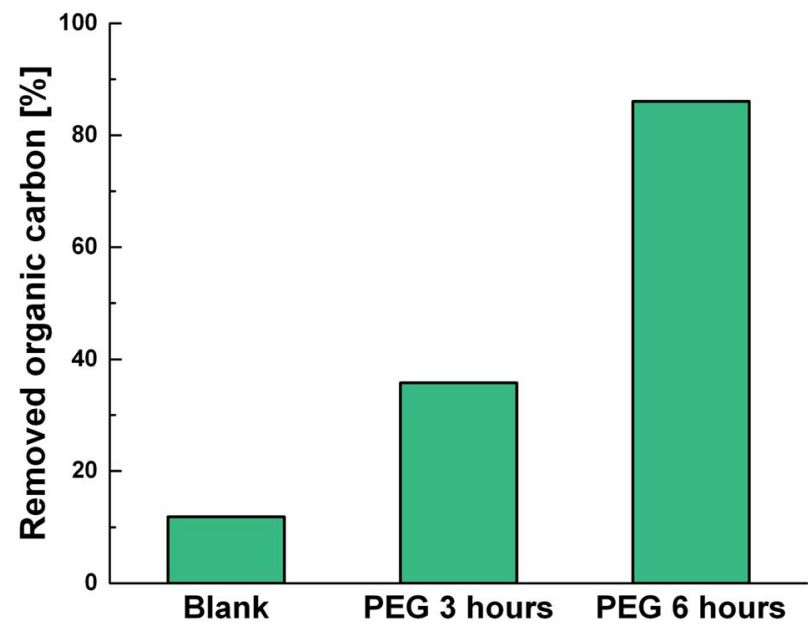

Fig. 9 TOC measurements of pristine PEG irradiated for 6 hours (Blank) and PEG treated with Ni-free/G-Porph rings after 3 hours (PEG 3 hours) and 6 hours (PEG 3 hours) of photoexposure. be better elucidated. In our experiments, samples of $1 \mathrm{~cm}^{2}$ of $\mathrm{Ni}$-free photocatalyst are immersed in MB solutions up to the adsorption-desorption equilibrium. Then, increasing volumes of trapping agents from $1 \mathrm{mg} \mathrm{L}^{-1}$ up to 10 and $15 \mathrm{mg} \mathrm{L}^{-1}$ are added to the solutions evaluating their inhibitory effect on $\mathrm{MB}$ degradation (Fig. 11 and S10-S13†). In Fig. 11 the degradation tests collected by adding $15 \mathrm{ppm}$ of trapping agents, together with the MB degradation trace of our sample are displayed, and compared. As it is possible to observe from Fig. 11, the addition of $t$-BuOH did not affect MB photo-degradation trend. On the contrary, when EDTA is added to the solution, the MB experienced only a decrement of $52 \%$ denoting as photogenerated holes took part to the process. Similarly, the presence of NBT and ABDA seem to determine inhibition of MB degradation. As well known, their scavenger effects can be referable to the presence of superoxide radical and singlet oxygen respectively. These findings are entirely in agreement with recent literature reporting similar systems, proposing also an increase of singlet oxygen quantum yield induced by 
(a)

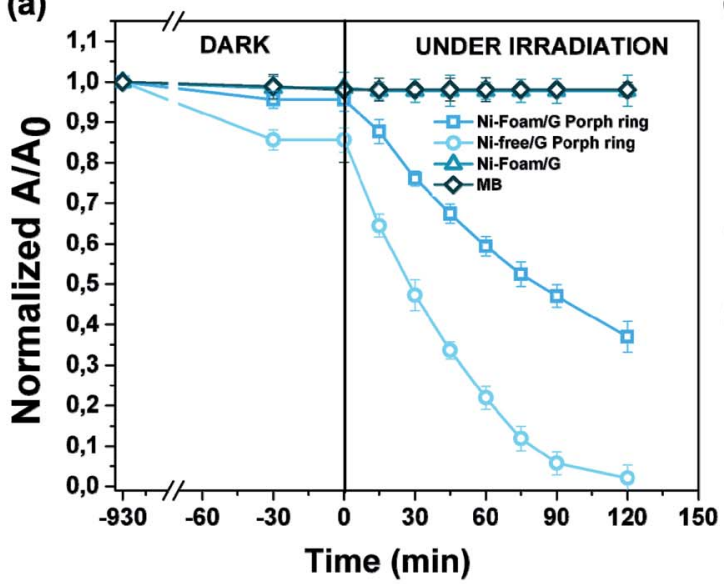

(b)

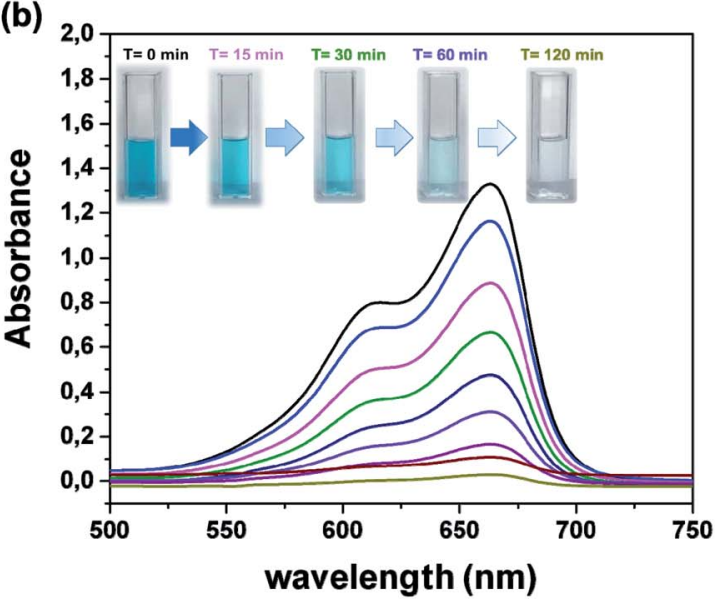

Fig. 10 (a) Photocatalytic activity of Ni-Foam/G, Ni-Foam/G-Porph rings, Ni-Free/G-Porph rings toward the degradation of MB after 120 minutes of light irradiation; (b) time dependent absorption changes of MB upon visible irradiation in the presence of Ni-free/G-Porph ring.

graphene-porphyrin $\pi-\pi$ interactions. ${ }^{23,54}$ On the basis of these experimental data, MB degradation mechanisms of the Ni-free/G-Porph rings are here proposed in Fig. 12.

The work function $(E)$ of graphene versus vacuum can be calculated to be about $4.42 \mathrm{eV} .{ }^{34}$ Considering the previous reported electrochemical measurements, we can also assign and plot the LUMO $(-4.2 \mathrm{eV})$ and HOMO $(-6.64 \mathrm{eV})$ energy levels of our sample. Based on these data, the light-excited porphyrin electrons can be excited from its $\mathrm{S}_{0}$ to the $\mathrm{S}_{1}{ }^{*}$ LUMO level. Here, the excited state $S_{1}^{*}$ can involve ISC resulting in a first excited tripled state $\mathrm{S}_{3}{ }^{*}$ as shown in eqn (1). Supported by the literature, we can reasonable suppose that this process is also facilitated by the presence of graphene, which can prevent the $\mathrm{S}_{3}{ }^{*}$ physical deactivation ${ }^{48}$ and the electron-hole recombination between $\mathrm{S}_{1}{ }^{*}$ and the porphyrin ground state. ${ }^{54,57}$ Since $\mathrm{S}_{3}{ }^{*}$ has a longer lifetime than $\mathrm{S}_{1}{ }^{*},{ }^{7}$ it can transfer its energy to another molecule. In the presence of oxygen, $\mathrm{S}_{3}{ }^{*}$ transfers its energy to the oxygen triplet ground state, producing singlet oxygen (2).

$$
\begin{gathered}
\mathrm{P}\left(S_{1}{ }^{*}\right) \rightarrow \mathrm{P}\left(S_{3}{ }^{*}\right) \\
\mathrm{P}\left(S_{3}{ }^{*}\right)+{ }^{3} \mathrm{O}_{2} \rightarrow \mathrm{P}\left(S_{0}\right)+{ }^{1} \mathrm{O}_{2}
\end{gathered}
$$

At the same time, $\mathrm{S}_{3}{ }^{*}$ can transfer electrons to oxygen (3) as well as graphene, generating superoxide radicals $\left(\mathrm{O}_{2}{ }^{-}{ }^{-}\right)$, in accordance with our radical-trapping experiments.

$$
\mathrm{P}\left(\mathrm{S}_{3}^{*}\right)+\mathrm{O}_{2} \rightarrow \mathrm{P}^{+}+\mathrm{O}_{2}^{--}
$$
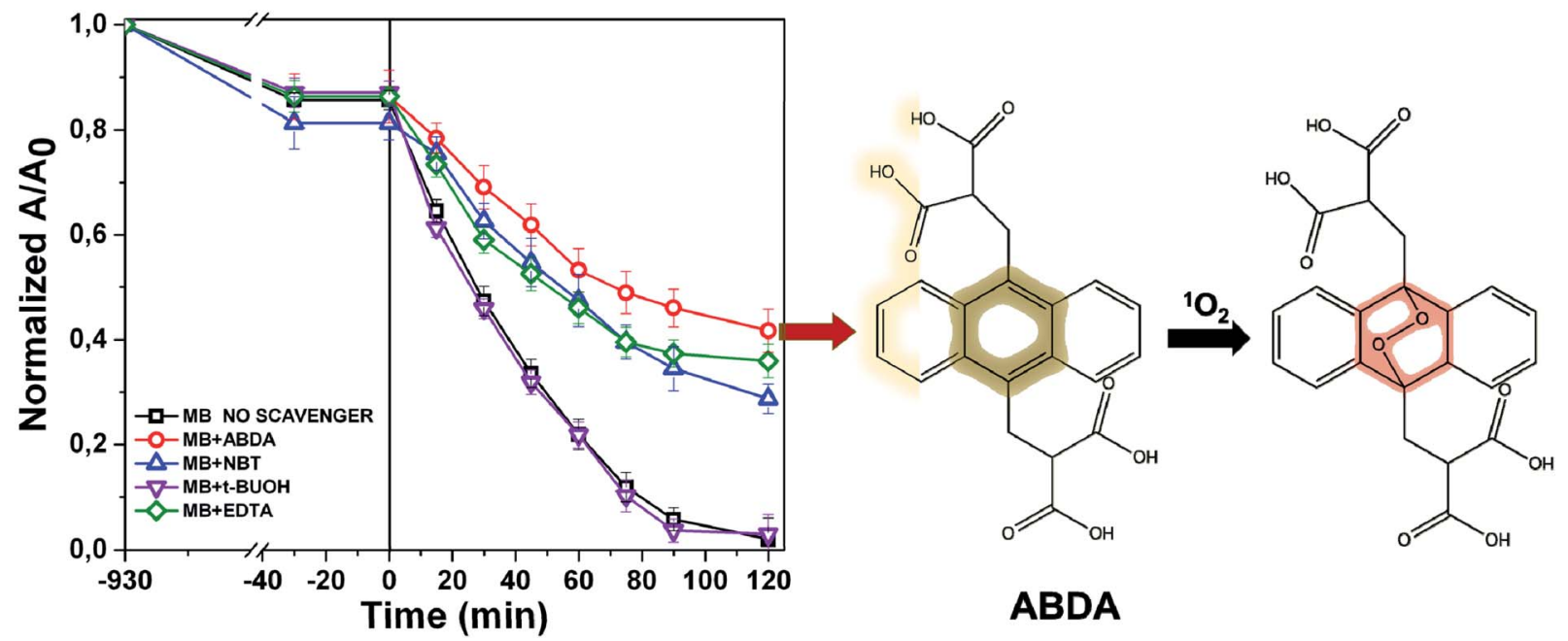

Fig. 11 Effect of ABDA, NBT, EDTA and $t-\mathrm{BuOH}$ radical-hole scavengers on the degradation rate of $\mathrm{MB}$ by using the Ni-free/G-Porph rings sample. The inhibition of the MB degradation due to the ABDA oxidation indicates the effective ROS production during 120 minutes of irradiation time. Among the produced $\mathrm{ROS},{ }^{1} \mathrm{O}_{2}$ constitutes the predominant species. 


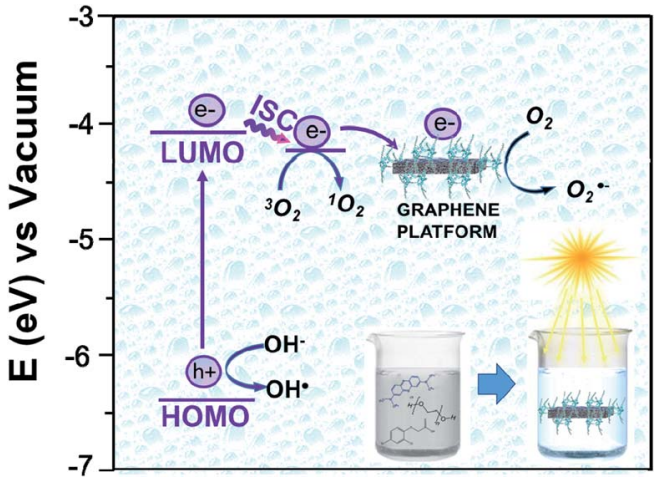

Fig. 12 Energy diagram of the proposed mechanism for the photocatalytic degradation of MB by using Ni-free/G-Porph rings as organic photosensitizer.

\section{Conclusions}

The hybrid Ni-free/graphene-Porph rings (Ni-free/G-Porph rings) was here proposed as a new photocatalytic system. The spin-coated photocatalyst was able to protect $\mathrm{G}$ during the $\mathrm{Ni}$ etching from defects formation and collapse as well. At the same time, the desired $\pi-\pi$ interactions at the G/polymer interface, crucial to promote the electron transfer process were strongly achieved as confirmed by PL and photocatalytic degradation measurements. The freestanding material obtained after $\mathrm{Ni}$ removal, exhibited diverse photocatalytic performance depending on the selected target pollutant. Specifically, the $\mathrm{Ni}$ free device was able to degrade 2,4-D herbicide, without reaching mineralization. Differently, under the experimental condition used, the PEG sample was photodegraded and mineralized according to TOC results. The radical trapping tests performed by MB solution, confirmed that singlet oxygen is the predominant species, although the other ROS are also produced assisting the contaminants degradation. Finally, a detailed map of photo-mechanisms was reported, including the calculation of the Highest Occupied Molecular Orbital (HOMO) and Lowest Occupied Molecular Orbital (LUMO) energy level values of the photosensitizer, calculated by the electrochemical study.

\section{Experimental}

\subsection{Materials and reagents}

All solvents and basic materials were commercial products appropriately purified before use.

All chemicals were used as received, unless otherwise noted. 5,10-di[ $p$-(9-methoxytriethylenenoxy)phenyl $]-15,20-d i[p$ -

hydroxyphenyl]-porphyrin and 1,20-di(bisphenoxy-A) eicosane monomer were synthesized and characterized according to our previous report ${ }^{19}$ (Table S1, $\dagger$ Fig. S1 $\dagger$ ). Nickel foam is purchased from GoodFellow with following features: $0.45 \mathrm{~g}$ $\mathrm{cm}^{-2}$, porosity $95 \%, 20$ pores per $\mathrm{cm}$, purity $95 \%$ and $1.6 \mathrm{~mm}$ thickness.

\subsection{Molar masses determination}

Size Exclusion Chromatography (SEC) analyses were performed by using a Waters 515 HPLC pump, having four Ultra-Styragel HR columns in series (in the order: HR4, HR3, HR2 and HR1), and a Waters R401 differential refractometer. $1 \mathrm{mg} \mathrm{ml}^{-1}$ of THF solutions, were introduced at a flow rate of $1 \mathrm{~mL} \mathrm{~min}^{-1}$. Calibration points were acquired by using selected polymethylmethacrylate references.

\subsection{Electrospray ionization mass spectrometry}

ESI mass analysis was performed by an Orbitrap Exactive mass spectrometry equipped by a H-ESI source. Mass spectra were acquired in negative ion mode in the $m / z$ range $150-225$ under the following conditions: capillary temperature $130{ }^{\circ} \mathrm{C}$, nebulizer gas (nitrogen) with a flow rate of 15 arbitrary units; source voltage $4 \mathrm{kV}$; capillary voltage $46 \mathrm{~V}$; tube lens voltage $90 \mathrm{~V}$. After photodegradation process, each samples was injected (direct infusion) at a flow rate of $10 \mu \mathrm{L} \mathrm{min}{ }^{-1}$. The mass spectrometer was calibrated using a standard mixture sodium dodecyl sulfate (265.17 Da), Ultramark (1621 Da) and sodium taurocholate (51 $442 \mathrm{Da})$.

\subsection{Matrix assisted laser desorption ionization-time of flight (MALDI-TOF)}

Spectra were acquired in reflector positive-ion mode using a 4800 MALDI TOF/TOF ${ }^{\mathrm{TM}}$ Analyzer, supplied with a Nd : YAG laser. Mass calibration was obtained by means of a set of polypeptides having different molar masses. Sample preparation was achieved by mixing $0.1 \mathrm{mmol}$ of analytes and $40 \mathrm{mmol}$ of trans-3-indoleacrylic acid for porphyrin polymers sample and trans-2-[3-(4-tert-butylphenyl)-2-2-methyl-2-propenylidene] malononitrile for PEG, using THF as a solvent for both polymers.

\subsection{Determination of total organic carbon (TOC)}

The mineralization of the pollutants after irradiation in the presence of samples was evaluated by measuring the TOC content with a TOC analyzer (Shimadzu TOC-LCSH) equipped with a non-dispersive infrared detector.

\subsection{Inductively coupled plasma-mass spectrometry (ICP-MS)}

ICP-MS analysis was performed by using a NEXION 300X (PerkinElmer). A piece of $1 \mathrm{~cm}^{2}$ of Ni-free/3DG copolymer was mineralized (700 W, 40 minutes). $10 \mathrm{ppb}$ of internal standard (Multielement standard solution for ICP-TraceCERT®) was added.

\subsection{X-ray photoelectron spectroscopy (XPS) analysis}

Multi technique spectrometer PHI ESCA/SAM 5600 equipped with $\mathrm{Mg}$ standard X-ray source was used to obtain XPS data. The measurements were setted at $45^{\circ}$ photoelectron take-off angle in relation to the target sample with an angle of $\pm 3^{\circ}$. was set at $23.5 \mathrm{eV}$ for high-resolution spectra were collected by fixing at $23.5 \mathrm{eV}$. The analyzer pass energy. Calibration of the binding 
energy (BE) was achieved by centering the C 1s peak at $285.0 \mathrm{eV}$. The analyses were executed on $2 \mathrm{~mm}$ diameter surface area of the sample.

\subsection{Scanning electron microscopy (SEM) analysis}

Hybrid structure morphologies were obtained by scanning electron microscopy (SEM, Gemini 152 field emission SEM Supra 25, Carl Zeiss, Germany) working at $2.0 \mathrm{kV}$, in the inlens operation mode.

\subsection{Photoluminescence (PL) analyses}

PL measurements were performed by sampling the same surface areas of the photocatalyst and reference as well $\left(1 \mathrm{~cm}^{2}\right)$, at room temperature by an $\mathrm{He}-\mathrm{Cd}$ laser (excitation wavelength of $325 \mathrm{~nm}$ ). PL signals have been recorded by a monochromator and a water-cooled Hamamatsu photomultiplier.

\subsection{Synthesis of nickel/graphene foam (Ni/G)}

Synthesis of Ni-G samples was performed in AIXTRON's Black Magic Chemical Vapor Deposition (CVD) system. ${ }^{19}$ Systems were heated at $900{ }^{\circ} \mathrm{C}$ for 20 minutes under $\mathrm{Ar}$ and $\mathrm{H}_{2}$ flows (600 and $400 \mathrm{sccm}$, respectively) to eliminate the residual thin surface oxide layer before graphene growth. After, the chamber was heated up to $1000{ }^{\circ} \mathrm{C}$ and the $\mathrm{CH}_{4}$ flow was opened for 40 minutes (flow rates of 20, 600 and $1000 \mathrm{sccm}$ for $\mathrm{CH}_{4}$, $\mathrm{Ar}$ and $\mathrm{H}_{2}$, respectively) and then cooled down at $15^{\circ} \mathrm{C} \mathrm{min}^{-1}$ to grow the graphene layers on the Ni foam surface.

Characterization of graphene in terms of quality and number of layers was performed by Raman spectra. ${ }^{19}$

\subsection{Ni free-G/porph rings preparation}

About $10 \mathrm{mg}$ of Porph rings was dissolved in $1 \mathrm{~mL}$ of dimethylformamide (DMF). G pieces of $1 \mathrm{~cm}^{2}$ were covered by spincoating a DMF solution $10 \mathrm{mg} \mathrm{mL}^{-1}$ of porph rings. The specimens were dried on a hot plate $\left(80^{\circ} \mathrm{C}\right)$ for 40 minutes and overnight in a under vacuum oven at $60^{\circ} \mathrm{C}$. Then, samples were immersed in $\mathrm{HCl}(1 \mathrm{M})$ for 12 hours. Finally, after washing in fresh distilled water the samples were dried in oven for two hours at $45{ }^{\circ} \mathrm{C}$.

\subsection{Cyclic voltammetry measurements}

Electrochemical analyses were performed to measure the HOMO and LUMO energy values of the Porph rings by using a potentiostat (VersaSTAT 4, Princeton Applied Research, USA) and a three-electrode setup with $\mathrm{Pt}$ wires as working and counter electrodes, a saturated calomel electrode (SCE) as reference electrode and $0.1 \mathrm{M}$ tetrabutylammoniumhexafluorophosphate (TBAPF6) as supporting electrolyte. The experiments were carried out on three different dichloromethane solutions containing $1 \mathrm{mg}$ of porphyrin copolymer, $1 \mathrm{mg}$ of porphyrin monomer (Fig. S3†) and TBAPF6 (Fig. S4 $\dagger$ ). For each experiment dichloromethane solvent was preventively passed in molecular sieves and ferrocene was used as an internal standard (Fig. S5 $\dagger$ ). To evaluate the HOMO energy level we measured the optical bandgap $\left(E_{\mathrm{g}}\right)$ from the maximum value of the $Q_{y}(0,0)$ absorption band (554 nm) of UV-Vis spectrum of Porph rings (Fig. S6 $\dagger$ ) by using $E_{\mathrm{g}}=h c / \lambda_{\text {onset }}$ where $h$ is the Planck constant $\left(6.63 \times 10^{-34} \mathrm{~m}^{2} \mathrm{~kg} \mathrm{~s}^{-1}\right)$ and $c$ is the speed of light $\left(3 \times 10^{8} \mathrm{~m} \mathrm{~s}^{-1}\right)$.

\subsection{Photocatalytic tests}

The photocatalytic efficiency of the hybrid material was evaluated versus 2,4 D, PEG having a $M_{\mathrm{n}} 1900 \mathrm{Da}$, as well as MB water solutions under visible-light irradiation. All solutions were saturated by bubbling air every 10 minutes per hours, and were irradiated by the solar simulator VeraSol-2 from Oriel by Newport corresponding to AM1.5 G in the visible and near-infrared region (400-1100 $\mathrm{nm}$ ) with a light irradiance of $100 \pm 3 \mathrm{~mW}$ $\mathrm{cm}^{-2}$. Specifically, MB degradation tests were performed by removing the irradiation in the range 600-700 $\mathrm{nm}$ to suppress MB absorption (see Fig. S14 $\dagger$ ). A $1 \mathrm{~cm}^{2}$ sample was immersed in $2 \mathrm{~mL}$ of the target solution $(0.015 \mathrm{Mm})$ and left overnight in the dark up to the adsorption-desorption equilibrium. The variation of MB concentrations was spectrophotometrically evaluated observing the absorption at $664 \mathrm{~nm}$. The photodegradation ratio was defined as $\left(A_{0}-\mathrm{A}\right) / A_{0}$ where $\mathrm{A}$ is the absorption of the dye at a certain time and $A_{0}$ represents the absorption value of the MB initial concentration.

With regards to 2,4-D photodegradation tests, $1 \mathrm{~cm}^{2}$ of device was immersed in $2 \mathrm{~mL}$ of herbicide solution $(0.005 \mathrm{mM})$ and irradiated for 6 hours. Control experiments were carried out in the dark for 30 minutes to ensure the adsorption-desorption equilibrium of the herbicide. The photodegradation products were determined by the ESI-MS as well as UV-Vis measurements, following also the degradation by UV-Vis and TOC analyses.

Finally, to evaluate the photodegradation ability versus polyethylene-oxide (PEG), $1 \mathrm{~cm}^{2}$ of speciment was immersed in $2 \mathrm{~mL}$ of polymer aqueous solution $\left(0.5 \mathrm{mg} \mathrm{mL}^{-1}\right)$. To estimate the photodegradation process, MALDI-TOF spectra were acquired up to 6 hours of photoexposure, while mineralization of PEG was monitored by measuring the TOC. Tests in absence of photocatalysts were also performed as black reference.

\subsection{Radical trapping measurements}

$1 \mathrm{~mL}$ of $\mathrm{MB}$ aqueous solutions $\left(1 \times 10^{-5} \mathrm{M}\right)$ were mixed with $1 \mathrm{~mL}$ of radical- and hole-trapping agent solutions $\left(1 \times 10^{-3} \mathrm{M}\right)$ with absorbance adjusted around 1.0. When the adsorptiondesorption equilibrium was reached, all mixed solutions were saturated by bubbling air for 15 minutes for each hour. The cuvettes were exposed to the solar simulation in the same conditions reported above for the photocatalytic test. The MB degradation rate was evaluated by monitoring the absorbance values at $664 \mathrm{~nm}$ for two hours. Triplicate data was collected for each irradiation time.

\section{Author contributions}

M. U. and S. C. C. conceived the project and wrote the manuscript. M. U. carried out the SEM images, realized the photocatalytic experiments and analyzed the collected data. M. 
U., G. C. and D. V. synthesized and characterized the porphyrin copolymer. M. U. and E. B. performed graphene preparation, characterization and developed the etching time-saving procedure. M. Ur. carried out the electrochemical measurements; M. M. made the photoluminescence experiments and G. C. produced the XPS spectra. M. C. carried out the TOC measurements and analyzed the data. S. C. C. and V. P. supervised the project. All the authors reviewed and commented on the manuscript at all stages.

\section{Conflicts of interest}

There are no conflicts to declare.

\section{Acknowledgements}

This work was funded by the European Regional Development Funds (FESR) INTERREG V - A Italia Malta - Micro WatTS C11.1-70.

\section{References}

1 P. J. J. Alvarez, C. K. Chan, M. Elimelech, N. J. Halas and D. Villagrán, Emerging opportunities for nanotechnology to enhance water security, Nat. Nanotechnol., 2018, 13, 634641.

2 M. A. Hassaan and A. E. Nemr, Health and Environmental Impacts of Dyes: Mini Review, American Journal of Environmental Science and Engineering, 2017, 1(3), 64-67.

3 M. Ussia, A. Di Mauro, T. Mecca, F. Cunsolo, G. Nicotra, C. Spinella, et al., ZnO-pHEMA Nanocomposites: An Ecofriendly and Reusable Material for Water Remediation, ACS Appl. Mater. Interfaces, 2018, 10, 40100-40110.

4 S. N. Ahmed and W. Haider, Heterogeneous photocatalysis and its potential applications in water and wastewater treatment: a review, Nanotechnology, 2018, 29, 34200.

5 L. Zhao, J. Deng, P. Sun, J. Liu, Y. Ji, N. Nakada, Z. Qiao, H. Tanaka and Y. Yang, Nanomaterials for treating emerging contaminants in water by adsorption and photocatalysis: systematic review and bibliometric analysis, Sci. Total Environ., 2018, 627, 1253-1263.

6 L. Prieto-Rodriguez, I. Oller, N. Klamerth, A. Aguera, E. M. Rodriguez and S. Malato, Application of solar AOPs and ozonation for elimination of micropollutants in municipal wastewater treatment plant effluents, Water Res., 2013, 47, 1521-1528.

7 V. Homem and L. Santos, Degradation and removal methods of antibiotics from aqueous matrices: A review, J. Environ. Manage., 2011, 92, 2304-2347.

8 M. Nowakowska and K. Szczubiałka, Photoactive polymeric and hybrid systems for photocatalytic degradation of water pollutants, Polym. Degrad. Stab., 2017, 145, 120-141.

9 M. L. Marin, L. Santos-Juanes, A. Arques, A. M. Amat and M. A. Miranda, Organic photocatalysts for the oxidation of pollutants and model compounds, Chem. Rev., 2012, 112.

10 D. M. Marin, S. A. L. Payerpaj, G. Ortiz, M. J. Singh and M. G. Walter, Efficient intersystem crossing using singly halogenated carbomethoxyphenyl porphyrins measured using delayed fluorescence, chemical quenching, and singlet oxygen emission, Phys. Chem. Chem. Phys., 2015, 17, 29090.

11 S. Mandal, S. K. Nayak, S. Mallampalli and A. Patra, Surfactant-Assisted Porphyrin Based Hierarchical Nano/ Micro Assemblies and Their Efficient Photocatalytic Behavior, ACS Appl. Mater. Interfaces, 2014, 6(1), 130-136.

12 L. Zhang, J. Lei, F. Ma, P. Ling, J. Liua and H. Ju, A porphyrin photosensitized metal-organic framework for cancer cell apoptosis and caspase responsive theranostics, Chem. Commun., 2015, 51, 10831-10834.

13 M. Thandu, C. Comuzzi and D. Goi, Phototreatment of Water by Organic Photosensitizers and Comparison with Inorganic Semiconductors, Int. J. Photoenergy, 2015, 2015, 1-22.

14 N. Zhang, M. Q. Yang, S. Liu, Y. Sun and Y. J. Xu, Waltzing with the Versatile Platform of Graphene to Synthesize Composite Photocatalysts, Chem. Rev., 2015, 115(18), 10307-10377.

15 F. Perreault, A. Fonseca de Faria and M. Elimelech, Environmental applications of graphene-based nanomaterials, Chem. Soc. Rev., 2015, 44(16), 5861-5896.

16 Y. Chen, A. Li, Z.-H. Huang, L.-N. Wang and F. Kang, Porphyrin-Based Nanostructures for Photocatalytic Applications, Nanomaterials, 2016, 6(3), 51.

17 D. M. Guldi, G. N. A. Rahman, J. Ramey, M. Marcaccio, D. Paolucci, F. Paolucci, et al., Donor-acceptor nanoensembles of soluble carbon nanotubes, Chem. Commun., 2004, (18), 2034-2035.

18 K. C. Kemp, H. Seema, M. Saleh, N. H. Le, K. Mahesh, V. Chandra, et al., Environmental applications using graphene composites: water remediation and gas adsorption, Nanoscale, 2013, 5(8), 3149.

19 M. Ussia, E. Bruno, E. Spina, D. Vitalini, G. Pellegrino, F. Ruffino, et al., Freestanding photocatalytic materials based on 3D graphene and polyporphyrins, Sci. Rep., 2018, 1-12.

20 S. M. Aly, M. R. Parida, E. Alarousu and O. F. Mohammed, Ultrafast electron injection at the cationic porphyrin graphene interface assisted by molecular flattening, Chem. Commun., 2014, 50, 10452-10455.

21 M. Zhu, Z. Li, B. Xiao, Y. Lu, Y. Du, P. Yang, et al., Surfactant Assistance in Improvement of Photocatalytic Hydrogen Production with the Porphyrin Noncovalently Functionalized Graphene Nanocomposite, ACS Appl. Mater. Interfaces, 2013, 5(5), 1732-1740.

22 G. Niu, H. Wang, P. Wang, Q. Jia, W. Liu, L. Guo, et al., A graphene quantum dot photodynamic therapy agent with high singlet oxygen generation, Nat. Commun., 2014, 5, 5496.

23 M. Managa, B. P. Ngoy and T. Nyokong, New J. Chem., 2019, 4518-4524.

24 N. T. Dintcheva, R. Arrigo, S. C. Carroccio, G. Curcuruto, C. Guenzi, C. G. Gambarotti, et al., Multi-functional polyhedral oligomeric silsesquioxane-functionalized carbon nanotubes for photo-oxidative stable Ultra-High 
Molecular Weight Polyethylene-based nanocomposites, Eur. Polym. J., 2016, 75, 525-537.

25 R. Arrigo, S. Bellavia, C. Gambarotti, N. T. Dintcheva and S. Carroccio, Carbon nanotubes-based nanohybrids for multifunctional nanocomposites, J. King Saud Univ., Sci., 2017, 29(4), 502-509.

26 Y. Qiu, Z. Wang, A. C. E. Owens, I. Kulaots, Y. Chen, A. B. Kane, et al., Antioxidant chemistry of graphene-based materials and its role in oxidation protection technology, Nanoscale, 2014, 6, 11744-11755.

27 S. W. Crowder, D. Prasai, R. Rath, D. A. Balikov, H. Bae, K. I. Bolotin, et al., Three-dimensional graphene foams promote osteogenic differentiation of human mesenchymal stem cells, Nanoscale, 2013, 5(10), 4171-4176.

28 Y. Zhang, L. Zhang and C. Zhou, Review of chemical vapor deposition of graphene and related applications, Acc. Chem. Res., 2013, 46, 2329-2339.

29 P. Qiua, J. Yaoa, H. Chena, F. Jianga and X. Xieb, Enhanced visible-light photocatalytic decomposition of 2,4dichlorophenoxyacetic acid over $\mathrm{ZnIn}_{2} \mathrm{~S}_{4} / \mathrm{g}-\mathrm{C}_{3} \mathrm{~N}_{4}$ photocatalyst, J. Hazard. Mater., 2016, 317, 158-168.

30 R. Fiorenza, A. Di Mauro, M. Cantarella, C. Iaria, E. M. Scalisi, M. V. Brundo, A. Gulino, L. Spitaleri, G. Nicotra, S. Dattilo, S. C. Carroccio, V. Privitera and G. Impellizzeri, Preferential removal of pesticides from water by molecular imprinting on $\mathrm{TiO}_{2}$ photocatalysts, Chem. Eng. J., 2020, 379, 122309.

31 J. A. Giroto, A. C. S. C. Teixeira, C. A. O. Nascimento and R. Guardani, Degradation of Poly(ethylene glycol) in Aqueous Solution by Photo-Fenton and $\mathrm{H}_{2} \mathrm{O}_{2} / \mathrm{UV}$ Processes, Ind. Eng. Chem. Res., 2010, 49, 3200-3206.

32 S. P. Vijayalakshmi and G. Madras, Photocatalytic Degradation of Poly(ethylene oxide) and Polyacrylamide, $J$. Appl. Polym. Sci., 2006, 100, 3997-4003.

33 F. Hassouna, G. Mailhot, S. Morlat-Therias and J. L. Gardette, Photochemical behaviour of poly(ethylene oxide) (PEO) in aqueous solution: Influence of iron salts, $J$. Photochem. Photobiol., A, 2008, 195, 167-174.

34 S. Morlat and J. L. Gardette, Phototransformation of watersoluble polymers. Part II: photooxidation of poly(ethylene oxide) in aqueous solution, Polymer, 2003, 44, 7891-7897.

35 K. Ding, Y. Zhang, W. Si, X. Zhong, Y. Cai, J. Zou, et al., Zinc(II) Metalated Porphyrins as Photothermogenic Photosensitizers for Cancer Photodynamic/Photothermal Synergistic Therapy, ACS Appl. Mater. Interfaces, 2018, 10, 238-247.

36 H. Seema, K. C. Kemp, V. Chandra and K. S. Kim, Graphene$\mathrm{SnO}_{2}$ composites for highly efficient photocatalytic degradation of methylene blue under sunlight, Nanotechnology, 2012, 23, 355705.

37 A. Reina, X. Jia, J. Ho, D. Nezich, H. Son, V. Bulovic, et al., Large Area, Few-Layer Graphene Films on Arbitrary Substrates by Chemical Vapor Deposition, Nano Lett., 2009, 9(1), 30-35.

38 M. Ussia, F. Ruffino, E. Bruno, E. Spina, I. Conticello, V. Privitera, et al., The role of solvent on the formulation of Graphene/polyporphyrin hybrid material versus photocatalytic activity, Polym. Bull., 2019, 1-15.

39 Z. Chen, C. Xu, C. Ma, W. Ren and H. Cheng, Lightweight and Flexible Graphene Foam Composites for HighPerformance Electromagnetic Interference Shielding, Adv. Mater., 2013, 25(9), 1296-1300.

40 Z. Chen, W. Ren, L. Gao, B. Liu, S. Pei and H. Cheng, Threedimensional flexible and conductive interconnected graphene networks grown by chemical vapour deposition, Nat. Mater., 2011, 10, 424-428.

41 G. Pellegrino, G. Condorelli, V. Privitera, B. Cafra, S. Di Marco and A. Alberti, Dye-sensitizing of selfnanostructured $\mathrm{Ti}(: \mathrm{Zn}) \mathrm{O}_{2} / \mathrm{AZO}$ transparent electrodes by self-assembly of 5,10,15,20-tetrakis(4-carboxyphenyl) porphyrin, J. Phys. Chem. C, 2011, 115(15), 7760-7767.

42 H. Yamashige, S. Matsuo, T. Kurisaki, R. C. C. Perera and H. Wakita, Local Structure of Nitrogen Atoms in a Porphine Ring of meso - Phenyl Substituted Porphyrin with an Electron-Withdrawing Group Using X-ray Photoelectron Spectroscopy and X-ray Absorption Spectroscopy, Anal. Sci., 2005, 21, 635-639.

43 O. Bajjou, P. N. Mongwaketsi, M. Khenfouch, A. Bakour, M. Baïtoul, M. Maaza, et al., Photoluminescence Quenching and Structure of Nanocomposite Based on Graphene Oxide Layers Decorated with Nanostructured Porphyrin, Nanomater. Nanotechnol., 2015, 5(7), 1-6.

44 A. Wojcik and P. V. Kamat, Reduced Graphene Oxide and Porphyrin, An Interactive Affair in 2-D, 2010, 4, 6697-6706.

45 O. F. Mohammed, V. A. Melnikov and O. F. Mohammed, Chem. Commun., 2015, 51, 8010-8013.

46 P. Monge, D. Moonshiram, P. Garrido-Barros, C. GimbertSuriñach, V. S. Batista, A. Llobet, et al., Electronic $\pi$ Delocalization Boosts Catalytic Water Oxidation by $\mathrm{Cu}$ (II) Molecular Catalysts Heterogenized on Graphene Sheets, $J$. Am. Chem. Soc., 2017, 139(37), 12907-12910.

47 L. Leonat, G. Sbarcea and I. V. Branzoi, Cyclic voltammetry for energy levels estimation of organic materials, UPB Sci Bull Ser B, 2013, 75, 111-118.

48 A. Shafiee, M. M. Salleh and M. Yahaya, Determination of HOMO and LUMO of [6, 6]-phenyl C61-butyric acid 3ethylthiophene ester and poly (3-octyl-thiophene-2, 5-diyl) through voltametry characterization, Sains Malays., 2011, 40(2), 173-176.

49 L. Pan, B. Hu, X. Zhu, X. Chen, J. Shang, H. Tan, et al., Role of oxadiazole moiety in different $\mathrm{D}-\mathrm{A}$ polyazothines and related resistive switching properties, J. Mater. Chem. C, 2013, 1, 4556-4564.

50 H. Srour, T. H. Doan, E. Da Silva, R. J. Whitby and B. Witulski, Synthesis and molecular properties of methoxy-substituted diindolo [3, 2-b: 2', 3'-h] carbazoles for organic electronics obtained by a consecutive twofold Suzuki and twofold Cadogan reaction, J. Mater. Chem. C, 2016, 4, 6270-6279.

51 F. B. Dias, J. Santos, D. R. Graves, P. Data, R. S. Nobuyasu, M. A. Fox, et al., The role of local triplet excited states and D-A relative orientation in thermally activated delayed 
fluorescence: photophysics and devices, Adv. Sci., 2016, 3(12), 1600080.

52 H. Chen, Z. Zhang, Z. Yang, Q. Yang, B. Li and Z. Bai, Heterogeneous fenton-like catalytic degradation of 2,4dichlorophenoxyacetic acid in water with FeS, Chem. Eng. J., 2015, 273, 481-489.

53 N. Oturan, M. Panizza and M. A. Oturan, Cold Incineration of Chlorophenols in Aqueous Solution by Advanced Electrochemical Process Electro-Fenton. Effect of Number and Position of Chlorine Atoms on the Degradation Kinetics, J. Phys. Chem. A, 2009, 113, 10988-10993.

54 Q. Lu, Y. Zhang and S. Liu, Graphene quantum dots enhanced photocatalytic activity of zinc porphyrin toward the degradation of Methylene blue under visible-light irradiation, J. Mater. Chem. A, 2015, 3, 8552-8558.
55 Y. Chen, Z. H. Huang, M. Yueb and F. Kang, Integrating porphyrin nanoparticles into a $2 \mathrm{D}$ graphene matrix for free-standing nanohybrid films with enhanced visible-light photocatalytic activity, Nanoscale, 2014, 6, 978.

56 N. El-Shafai, M. E. El-Khouly, M. El-Kemary, M. Ramadan and M. Masoud, Self-assembly of porphyrin on graphene oxide in aqueous medium: fabrication, characterization, and photocatalytic studies, Photochem. Photobiol. Sci., 2019, Advance Article.

57 M. C. Derosa and R. J. Crutchley, Photosensitized singlet oxygen and its applications, Coord. Chem. Rev., 2002, 233234, 351-371.

58 Y. Nosaka and A. Y. Nosaka, Generation and Detection of Reactive Oxygen Species in Photocatalysis, Chem. Rev., 2017, 117, 11302-11336. 